\title{
The mechanical strength of orthodontic elastomeric memory chains and plastic chains: An in vitro study
}

\author{
Hubert Kardach ${ }^{1, A-F}$, Barbara Biedziak ${ }^{1, A-F}$, Aneta Olszewskaa ${ }^{1, B-D}$, Ewelina Golusińska-Kardach ${ }^{2, B-D}$, Jerzy Sokalski, A-F \\ 1 Division of Facial Malformation, Department of Dental Surgery, Poznan University of Medical Sciences, Poland \\ ${ }^{2}$ Department of Dental Surgery, Poznan University of Medical Sciences, Poland \\ A - research concept and design; $B$ - collection and/or assembly of data; $C$ - data analysis and interpretation; \\ $D$ - writing the article; $E$ - critical revision of the article; $F$ - final approval of article
}

\section{Address for correspondence}

Hubert Kardach

E-mail: hkardach@ump.edu.pl

\section{Funding sources}

None declared

\section{Conflict of interest}

None declared

Received on November 15, 2015

Revised on December 19, 2015

Accepted on February 25, 2016

DOI

\begin{abstract}
Background. The loss of physical properties of orthodontic chains has been a topic of discussion among scientists and clinicians, motivating efforts to improve elastic materials and minimize the decrease of force. Orthodontic companies have introduced memory elastomers, which, according to the manufacturers, have improved mechanical properties.
\end{abstract}

Objectives. The aim of the study was to evaluate the effects of stretching elastomeric chains submerged in $37^{\circ} \mathrm{C}$ artificial saliva.

Material and methods. The study assessed 2 types of chains. The first phase of the study evaluated 1) the tensile strength of the chains; and 2) elongation at the time of tearing in an environment outside of the oral cavity (without exposition). The second phase of the study evaluated 1) permanent deformation after stretching; 2) elongation at the time of tearing; and 3) the tensile strength of the chain in conditions similar to those present in the oral cavity.

Results. In the experiments using artificial saliva, pronounced force decay was observed in the plastic chain, in which, after just 7 days, force decreased almost by half compared to the initial value, with a continuous downward trend. The memory chain, however, showed increased elasticity, and after the first week of exposition the force decay at the time of tearing was around $20 \%$ of the initial value. Force decay at the time of tearing remained at a steady level between 14.4 and $25.4 \%$ throughout the whole period of exposition. In the plastic chain this value oscillated between 50.3 and 55.9\%. In the experiments assessing permanent deformation of the chains performed after each week of exposition, the specimens prepared from the memory chain stretched from $8 \mathrm{~cm}$ to approximately $9.5 \mathrm{~cm}$ after exposition, while the specimens prepared from the plastic chain stretched to approximately $13 \mathrm{~cm}$.

Conclusions. Memory chains are more effective in orthodontic treatment due to diminished loss of mechanical and elastic capabilities, when compared to plastic chains.

Key words: force decay, initial strain, tearing, stretching, elastic chain

10.17219/acem/61957

\section{Copyright}

Copyright by Author(s)

This is an article distributed under the terms of the

Creative Commons Attribution Non-Commercial License

(http://creativecommons.org/licenses/by-nc-nd/4.0/) 
The dynamic development of orthodontic techniques and products is allowing orthodontic therapy to reach new heights in positive treatment results, which in turn is making the use of permanent dental braces much more common.

The benefits of permanent dental braces include full control over dental alignment and precise use of forces, which makes them especially useful in treating dental anomalies and in interdisciplinary orthodontic, surgical and prosthetic treatment. Effective treatment is often not limited to the use of one type of brace; it frequently requires the implementation of precise and coordinated forces through the introduction of orthodontic archwires and supplementary elements.

Among those supplementary elements, elastic orthodontic elements called elastomers have been used for years. In addition to properties such as pliability and elasticity, elastomers are easy to use, reduce the risk of intraoral trauma, do not require the cooperation of patients and are cheap. They are produced in a wide variety of colors, and patients adapt to them easily during orthodontic treatment. Disadvantages include a decrease of force that is noticeable over time, difficulties in oral hygiene, increased dental plaque retention compared to metal elements and a loss of color through the absorption of fluid and dye from food. ${ }^{1}$ There are many types of elastomers, including, most commonly, separators, ligatures, rotation wedges, elastic threads and chains. They are an indispensable type of orthodontic accessory because they supply the force needed to move teeth, e.g. canine retraction and closing interdental spaces. Elastomers are most commonly made of 2 types of materials: natural or synthetic latex, the latter being increasingly more popular due to better mechanical and elastic properties, as well as the fact that more and more people are allergic to natural latex. Chains are produced as colorless or colored polyurethane elastomers with varying force (closed, short, long chains). Closed chains produce the biggest initial force. Less force is exerted by short chains in which the chain links are separated by short connectors. Even smaller forces are at play in long chains where the spaces between the chain links are longer. Loss of the initially generated force constitutes the biggest clinical problem. Studies have shown a $28-50 \%$ loss of initial force as early as $8 \mathrm{~h}$ after chain insertion into the oral cavity. After $24 \mathrm{~h}$, the rate of initial force loss decreases significantly but is still observed in the following 2 to 3 weeks. ${ }^{2-4}$ For practitioners, the correlation between the loss of force of the elastic elements and the time lapsed signifies that the chains need to be regularly changed every 5 to 6 weeks.

For years, the loss of physical properties of orthodontic chains has been a topic of discussion among scientists and clinicians, motivating efforts to improve elastic materials and minimize the decrease of force. Orthodontic companies have introduced memory elastomers which, according to the manufacturers, have improved mechani- cal properties. Elastomers used during orthodontic treatment are exposed to harsh conditions in the oral cavity, such as high temperature, significant humidity and spicy, highly seasoned food. These factors, apart from influencing the esthetics of the elastomers, significantly decrease their efficacy.

The aim of the study was to evaluate and compare the mechanical strength of elastomeric memory chains and plastic chains in in vitro conditions.

\section{Material and methods}

Two types of orthodontic chains - memory chain and plastic chain (American Orthodontics, Sheboygan, USA) - were chosen for the study. The type of factory in which the elastic materials are produced has a significant influence on their force decay. The composition and properties of the chains given by the manufacturers are often similar or nearly identical, but scientific studies show that the differences are very significant. For that reason, the materials chosen for this study were all manufactured by one company.

The study was carried out in 2 phases. The first phase of the study evaluated 1) the tensile strength of the chain and 2) elongation at the moment of tearing, both in an environment outside of the oral cavity (without exposition). The second phase of the study evaluated 1) the permanent deformation after stretching, 2) elongation at the moment of tearing and 3) the tensile strength of the chain, all in conditions similar to those present in the oral cavity. The specimens were constantly submerged in artificial saliva at $37^{\circ} \mathrm{C}$ over periods of up to 4 weeks; the procedure was repeated at weekly intervals $(\mathrm{t}=1$ week, 2 weeks, 3 weeks and 4 weeks).

The orthodontic elastic chains were subjected to the study within 2 weeks of delivery from the manufacturer's warehouse and were stored in a cupboard, at room temperature, in order to avoid UV radiation and excessive humidity prior to the experiments. Colorless chains were chosen for the study to eliminate the pigmentation effect in the elastic materials. ${ }^{5-7}$

A total of 35 specimens, $8 \mathrm{~cm}$ each, were taken from each type of chain. In the first phase of the study of the mechanical properties, both types of chain were placed, without exposition, in a Zwick 1445 Universal Testing System machine (Zwick GmbH, Ulm, Germany) and a tear test was performed at a cross-head speed of $50 \mathrm{~cm} / \mathrm{min}$. Additionally, an elongation-at-tear test was performed. All the tests were carried out by the same person, at room temperature.

In the second phase of study, $8 \mathrm{~cm}$ specimens of both chain types were stretched $100 \%$, i.e. to a length of $16 \mathrm{~cm}$. The stretched chains were then attached to mandrels and submerged in artificial saliva at $37^{\circ} \mathrm{C}$. The artificial 
saliva was prepared according to EU regulation PN-EN 12868:2001, paragraph 5.8.

After the exposition time lapsed - i.e. 1, 2, 3 or 4 weeks - the stress on the specimens was lifted. After being taken out of the artificial saliva, the chains were dried, and, after a 30-min rest, each specimen was measured in order to study the permanent deformation. An $8 \mathrm{~cm}$ section was then cut from the middle of each of the stretched, submerged and dried specimens and placed in the Universal Testing System machine, where a tear test was performed at a cross-head speed of $50 \mathrm{~cm} / \mathrm{min}$. Additionally, an elongation-at-tear test was performed. All the tests were carried out by the same person, at room temperature.

Data analyzed came from an interval scale and were shown as the mean value and standard deviation (mean $\pm \mathrm{SD})$. In order to compare the two independent groups (memory chains and plastic chains) Student's t-test was used. Compliance with normal distribution of data was verified using the Shapiro-Wilk test. Pairwise comparisons of strength and elongation when exposed to saliva and temperature were carried out using an analysis of variance (ANOVA). The post hoc Tukey's test was used when the results showed significant differences to determine homogeneous groups (Table 1). The statistical analysis was carried out using STATISTICA v. 10.0 software
(StatSoft Inc., Tulsa, USA). All the tests were analyzed at a significance level of $\alpha=0.05$

\section{Results}

The test results are presented in Tables 2-6. Table 2 shows the results of the tensile strength test for both memory chains and plastic chains, before exposition (time 0 ) and after submersion in artificial saliva after 1, 2, 3 and 4 weeks. The results show the mean force in newtons $(\mathrm{N})$ registered at the moment of tearing. The plastic chains exhibited more tensile strength than the memory chains did, and the difference was statistically significant. The force required to tear the plastic chains equaled $30.4 \mathrm{~N}$, which was $37.6 \%$ higher than the force needed to tear the memory chains. Time spent submerged in artificial saliva decreased the mechanical strength of both chain types. The biggest decrease in the force value necessary to break the plastic chains was registered after the $4^{\text {th }}$ week, while in case of the memory chains the biggest decrease was after the $1^{\text {st }}$ week. Furthermore, the difference between the memory chain's initial tensile strength and its tensile strength after 4 weeks of exposition decreased by almost $50 \%$. The changes in tensile strength are expressed as percentage values in Table 3.

Table 1. Pairwise comparison

\begin{tabular}{|c|c|c|c|c|}
\hline \multirow{3}{*}{$\begin{array}{l}\text { Comparison parameter } \\
\text { Tensile strenght } 0\end{array}$} & \multicolumn{3}{|c|}{ Tukey's pairwise comparison, alfa = 0.05} & \\
\hline & \multicolumn{2}{|c|}{ memory chain } & \multicolumn{2}{|c|}{ plastic chain } \\
\hline & & $\mathrm{b}$ & & b \\
\hline Tensile strenght 1 week & a & & a & b \\
\hline Tensile strenght 2 weeks & a & $\mathrm{b}$ & a & b \\
\hline Tensile strenght 3 weeks & a & & a & \\
\hline Tensile strenght 4 weeks & a & $\mathrm{b}$ & a & \\
\hline Elongation 0 & & & & b \\
\hline Elongation 1 week & a & $\mathrm{b}$ & a & \\
\hline Elongation 2 weeks & & $\mathrm{b}$ & a & \\
\hline Elongation 3 weeks & a & $\mathrm{b}$ & a & \\
\hline Elongation 4 weeks & a & & a & \\
\hline
\end{tabular}


Table 2. Tensile strenght

\begin{tabular}{|c|c|c|c|c|c|}
\hline $\begin{array}{c}\text { Tensile strenght } \\
\text { Mean (SD) }\end{array}$ & 0 & 1 week & 2 weeks & 3 weeks & 4 weeks \\
\hline Memory chain & $22.1(1.2)$ & $19.4(1.2)$ & $21.2(1.1)$ & $20.2(1.4)$ & $20.6(1.0)$ \\
\hline Plastic chain & $30.4(1.1)$ & $27.6(2.4)$ & $28.7(1.1)$ & $27.2(1.8)$ & $26.2(3.0)$ \\
\hline Student's t test - p value & $p<0.0001$ & $p<0.0001$ & $p<0.0001$ & $p<0.0001$ & 0.0006 \\
\hline
\end{tabular}

Table 3. Tensile strenght change

\begin{tabular}{|l|c|c|c|}
\hline Tensile strenght change \% & 1 week & 2 weeks & 3 weeks \\
\hline Memory chain & $19.4(1.2)$ & $21.2(1.1)$ & $20.2(1.4)$ \\
\hline Plastic chain & $27.6(2.4)$ & $28.7(1.1)$ & $27.2(1.8)$ \\
\hline
\end{tabular}

Table 4. Elongation

\begin{tabular}{|l|c|c|c|c|}
\hline \multicolumn{1}{|c|}{ Elongation \% (SD) } & 0 & 1 week & 2 weeks weeks & $333.3(27.5)$ \\
\hline Memory chain & $414(9.1)$ & $337(21.2)$ & $354.4(25.5)$ & $308.9(37.9)$ \\
\hline Plastic chain & $400.7(54.3)$ & $199(25)$ & $190.9(25.6)$ & $193(29.6)$ \\
\hline Student's t test $-\mathrm{p}$-value & 0.535002 & $p<0.0001$ & $p<0.0001 \quad p<0.0001$ \\
\hline
\end{tabular}

Table 5. Elongation change

\begin{tabular}{|c|c|c|c|c|}
\hline Elongation change \% & 1 week & 2 weeks & 3 weeks & 4 weeks \\
\hline Memory chain & -18.6 & -14.4 & -19.5 & -25.4 \\
\hline Plastic chain & -50.3 & -52.4 & -51.6 & -55.9 \\
\hline
\end{tabular}

Table 6. Permament deformation

\begin{tabular}{|l|c|c|c|c|}
\hline Permament deformation & 1 week & 2 weeks & 3 weeks & Avg weeks \\
\hline Memory chain & 9.3 & 9.7 & 9.5 & 9.4 \\
Plastic chain & 12.7 & 13.2 & 13.5 & 12.9 \\
\hline
\end{tabular}

Table 4 presents the results of the elongation-at-tear test for both types of chain. In the first phase of the study, without exposition, the memory chains showed better elastic properties than the plastic chains; however, the difference was not statistically significant.

In the tests conducted with artificial saliva a significant decrease of elongation was observed in the plastic chains. After just 7 days of exposition, the elongation-attear value was $50.3 \%$ of the initial value, with a tendency for further decrease. The memory chains, on the other hand, exhibited more elasticity and after the first week of exposition showed only a $20 \%$ decrease in the elongation-at-tear value when compared to the initial value. For the remainder of the exposition time, the decrease in the 
elongation-at-tear value of the memory chains stayed between 14.4 and $25.5 \%$. In case of the plastic chains, this value oscillated between 50.3 and $55.9 \%$ (Table 5). The statistically significant difference between those values points to the higher elasticity of the memory chains.

In the test for permanent deformation carried out after each week of exposition, the length of the specimens was measured 30 min after being removed from the mandrels. The memory chain specimens stretched from $8 \mathrm{~cm}$ to approximately $9.5 \mathrm{~cm}$ after 7 days of exposure and the plastic chain specimens stretched to approximately $13 \mathrm{~cm}$. Exposition time did not significantly influence the deformation values of either type of chain. The results are presented in Table 6.

\section{Discussion}

The hypothesis that elastomers are materials that remain stable throughout the entire time they are in the oral cavity and that they do not lose strength during treatment can be categorically rejected. The first studies and published results about decreases in the mechanical properties of elastomers appeared in the 1970s. The authors' own research points a gradually decreasing force in both plastic chains and in modified elastomers such as memory chains. It is worth mentioning that the latter exhibit greater elasticity and the decrease in elongationat-tear value was almost $50 \%$ of the decrease noted for the plastic chains. The problem of force decay in elastic orthodontic elements constitutes a significant clinical issue and is of interest to researchers. Different studies have reported force decay ranging from 24 to $85 \%$ after 28 days. ${ }^{8-14}$ Masoud et al. compared the mechanical properties of thermoplastic and thermoset elastic chains and found significant force decay in thermoplastic chains, on average $20 \%$ higher than in thermoset chains. ${ }^{15}$ Kersey et al. evaluated the strength of elastics, and showed that the force decay after $24 \mathrm{~h}$ equaled $17 \%$ and the value of the forces generated was lower than that given by the manufacturer. ${ }^{16}$ A study by Kanchana et al. found that the initial force in elastics decreases by $30 \%$ in the first hour. ${ }^{17}$ Mikulewicz et al. demonstrated that the rate of force relaxation in elastics after $24 \mathrm{~h}$ varies between 5.7 and $17.7 \%$, depending on type of elastic. ${ }^{18}$

Environmental factors such as water, fluids, saliva, food and temperature impact changes in the mechanical properties of elastic elements. Fraunhofer et al. demonstrated that the exposition of elastic chains to saliva and superficial fluoride necessitates an increase in length of elongation to generate $150 \mathrm{~g}$ and $300 \mathrm{~g}$ force. ${ }^{19}$

Josell et al. studied chains from several different manufacturers, and demonstrated that all the chains lose their physical qualities most rapidly on the first day or even the first hour of use. This trend then continues over 2-4 days. $^{20}$
During orthodontic treatment the elastic elements are stretched to generate force. Stretching a chain stresses the molecular polymer within it. The procedure initially strengthens the durability of the elastic chain and causes it to generate the force necessary for orthodontic treatment. ${ }^{21}$ This is possible because the material "wants" to return to its initial form and size. It is crucial for the material not to get stretched to its limits, as that will cause permanent deformation and excessive broadening. Quantifying the loss of physical properties depends on the speed and strength with which the material is stretched. With enough force applied it is possible to tear the material. Rock et al. showed that stretching the elastic elements $300 \%$ or more produces an unfavorable response that causes the material to reach its limit of elasticity. Stretching the material $200 \%$ is frequent in orthodontic treatment. ${ }^{22}$ Huget et al. demonstrated that stretching chains 50\% causes less force decay than stretching it 100 or $200 \% .^{23}$

The results obtained in the present study are consistent with the published work of authors worldwide. In both chain types, the biggest force decay was observed after the first 7 days. Subsequently it decreased slightly, remaining at a fairly constant level. A significantly lower loss of physical properties was observed in the memory chain. The authors of the study have confirmed, in contradiction to studies conducted by Ash et al. and Andreasen et al., that the loss of elastic properties also occurs when artificial saliva is used. ${ }^{24,25}$

The results of the present study confirm the need to exchange the elastic elements used in orthodontic treatment every 4 weeks in order to maintain a moderately constant force value. Memory chains are more effective in orthodontic treatment due to a lower rate of loss of mechanical and elastic properties when compared to plastic chains.

\section{References}

1. Buchamann N, Senn C, Ball J, Brauchli L. Influence of initial strain on the force decay of currently avaiable elastic chains over time. Angle Orthod. 2012;82(3):529-535.

2. Wong A. Orthodontic elastic materials. Angle Orthod. 1976;46:196-205.

3. Eliades T, Eliades G, Watts DC. Structurat conformation of in vitro and in vivo orthodontic elastomeric modules. Eur J Orthod. 1999;21:649-658.

4. Warych B. Akcesoria, Materiały i techniki ortodontyczne, Komorowska A, Polskie Towarzystwo Ortodontyczne. Lublin;2009:141-154.

5. Lu T C, Wang W N, Tarng T H, Chen J W. Force decay of elastomeric chain - a serial study. Part II. Am J Orthod Dentofacial Orthop. 1993;104:373-377.

6. Baty DL, Volz JE, von Fraunhofer JA. Force delivery properties of colored elastomeric modules. Am J Orthod Dentofacial Orthop. 1994;106:40-46.

7. Lew K. Staining of clear elastomeric modules from certain foods. J Clin Orthod. YEAR;24;472-474.

8. De Genowa DC, Mcinnes-Ledous P, Weinberg R Shaye R. Force degradation of orthodontic elastomeric chains - a product comparison study. Am J Orthod. 1985;87: 377-384.

9. Bousquet JA Jr, Tuesta O, Flores-Mir C. In vivo comparison of force decay between injection molded and die-cut stamped elastomers. Am J Orthod Dentofacial Orthop. 2006;129:384-389. 
10. Andreasen GF, Bishara SE. Comparison of Alastik chains with elastics involved with intra-arch molar to molar forces. Angle Orthod. 1970;40:151-158.

11. Bishara SE, Andreasen GF. A comparison of time related forces between plastic Alastiks and latex elastics. Angle Orthod. 1970; 40:319-328.

12. Stevenson J, Kusy R. Force application and decay characteristics of untreated and treated polyurethane elastomeric chains. Angle Orthod. 1994;64:455-467.

13. Kim KH, Chung CH, Choy K, Lee JS, Vanarsdall RL. Effects of prestretching on force degradation of synthetic elastometric chains. Am J Orthod Dentofacial Orthop. 2005;128:477-482.

14. Balhoff DA, Shuldberg M, Hagan JL, Ballard RW, Armbruster PC. Force decay of elastomeric chains - a mechanical design and product comparison study. J Orthod. 2011;38:40-47.

15. Masoud A, Tsay T, BeGole E, Bedra-Russo A. Force decay evaluation of thermoplastic and thermoset elastomeric chains. A mechanical design comparison. Angle Orthod. 2014;84(6):1026-1033.

16. Kersey ML, Glover KE, Heo G, Rabound D, Major PW. A comparison of dynamic and static testing of latex and nonlatex orthodontic elastics. Angle Orthod. 2003;73:181-186.
17. Kanchana P, Godfrey K. Calibration of force extension and force degradation characteristics of orthodontic latex elastics. Am J Orthod Dentofacial Orthop. 2000;118:280-287.

18. Mikulewicz M, Szymkowski J, Kossakowska P. Właściwości reologiczne ortodontycznych wyciągów elastycznych- doświadczenie in vitro. Dent Med Probl. 2008;445(4):420-424.

19. Fraunhofer JA, Coffelt MTP, Orbell GM. The effects of artificial saliva and topical fluoride treatments on the degradation of the elastic properties of orthodontic chains. Angle Orthod. 1992;62:265-274.

20. Josell SD, Leiss JB, Rekow ED. Force degradation in elastomeric chains. Semin Orthod. 1997;3(3):189-197.

21. Wong A. Orthodontic elastic materials. Angle Orthod. 1976;46:196-205.

22. Rock WP, Wilson HJ, Fisher SE. A laboratory investigation of orthodontic elastomeric chains. Br J Orthod. 1985;12:202-207.

23. Huget EF, Patrick KS, Nunez LJ. Observation on the elastic behavior of a synthetic orthodontic elastomer. J Dent Res. 1990;69:496-501.

24. Ash J, Nikolai R. Relaxation of orthodontic elastic chain and modules in vivo and in vitro. J Dent Res. 1978;57:685-690.

25. Andreasen GF, Bishara SE. Relaxation of othodontic elastomeric chains and modules in vitro and in vivo. Angle Orthod. 1970;40:319-328. 